\title{
Study on Viscoelastic Behavior of Carpet
}

\author{
Part 1: Apparatus for Dynamic Measurement in Simple Compression and Complex Dynamic \\ Modulus of Commercial Carpets \\ By Tsuneo Horino*, Tamotsu Yabunaka* and Masao Morikawa**, Members, TMSJ \\ Department of Textile Technology, Kyoto Technical University, Kyoto
}

Based on the Journal of the Textile Machinery Society of Japan, Transactions, Vol 23, No. 12, T264-272 (1970)

\begin{abstract}
Cut pile carpets consist of a pile yarn phase having volume fraction $\phi_{P}$ and a base fabric phase having $\phi_{B}$ coupled in series. Their complex dynamic compliance may be presented as additive of compliance of both phases on the assumption that the mechanical models of these phases take the Viogt ones.

Apparent values of complex dynamic modulus have been measured for commercial carpets within the frequency range from 0.05 to $1 \mathrm{~Hz}$. under compressive strains of less than $50 \%$ by means of Hysteresis loop method. The results obtained show that in the frequency range their values of the complex dynamic modulus are not dependent upon observed frequency but upon applied static strain.

The values of the complex dynamic modulus for the commercial carpets resemble these of rubber-like materials.
\end{abstract}

KEY WORDS: CARPETS, DYNAMIC MODULUS, POISSONS RATIO, HYSTERESIS (MECHANICAL)

\section{Introduction}

The increasing amount of commercial productions of carpets induces various fiber materials to be used for them.

The standard testing methods to evaluate some properties of carpets in term of end-use are not defined as yet. Therefore, mechanical properties of various carpets, e. g., compressive stress-strain relation and shearing stressstrain relation, have been measured by the use of an Instron type tensile tester and its attachments. ${ }^{[1,2]}$

In 1961, F. C. Aarper et $\mathrm{al}^{[3]}$ measured the forces applied on the floor during straight walking. They informed that compressive and shearing forces are imposed on the floor during walking.

This paper compares the compressive and shearing stress-strain curve of carpets with the magnitude of forces applied on the floor. The results show the deformation of carpet is produced mainly due to compressive stress.

In this paper, compressive viscoelastic behavior of commercial carpets is represented by apparent complex dynamic modulus.

\footnotetext{
*Present address: Saidaizi mill, Nihon Exlan Co., Ltd., Okayama, Okayama-ken, Japan

**Present address: Kusu mill, Toa Boshoku Co., Ltd., Mie-gun, Mie-ken, Japan
}

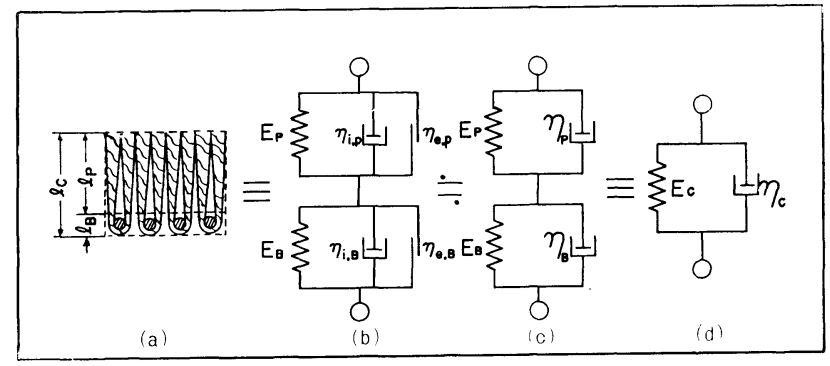

Fig. 1 Mechanical model of cut pile carpet

\section{Test Samples and Mechanical Model of Carpet}

Samples of carpet differing in fiber content, fiber material and construction have been prepared for use for testing. All test carpets are cut-piled. The pile yarns were spun from staple fibers of wool, polypropylene, acrylic and cordelan. The materials of pile yarns and measured properties of the carpet samples are detailed in Table 1. Carpet samples made of synthetic fibers were tufted with a double jute backing and latex adhesive. Wool carpets were woven with a jute base fabric.

Cut pile carpets consist of the following two phases coupled in series: a pile yarn phase having length $l_{P}$ and a base fabric phase having $l_{B}$ illustrated in Fig. 1-a. The 
dynamic mechanical behavior of each phase is viscoelasticity, which combines all of elasticity, internal and external viscosities. One analytical method is to use mechanical model, composed of ideal elastic spring, ideal viscous dash-pot and frictional slider. The springs will abide by Hooke's law, the dash-pots will follow Newton's law and the sliders will represent Columb friction. In each phase, a spring, a dash-pot and a slider are arranged in parallel, and pile yarn phase and base fabric one are connected to each other in series, as Fig. 1-b. shows.

In this experiment, a mechanical model of carpet is established on assumption that a spring and a dash-pot with internal and external frictions are connected in parallel in each phase, as shown in Fig. 1-c. If the mechanical models of two phases take Voigt models as shown in Fig. 1-c, the mechanical model of carpet can be put as a Voigt model as illustrated in Fig. 1-d.

When $E_{P} *$ and $E_{B} *$ are represented as dynamic complex modulus for these phases, respectively, dynamic complex modulus for carpet is given by eq. (1) ${ }^{[4]}$.

$$
E_{C}^{\times}=\left(\frac{\Phi_{P}}{E_{P}^{x}}+\frac{\Phi_{B}}{E_{B}^{x}}\right)_{,}^{-1} \Phi_{P}+\Phi_{B}=1
$$

where $\emptyset_{P}$ and $\emptyset_{B}$ are volume fraction of pile yarn phase and one of base fabric phase, respectively.

Fig. 2 shows the compressive deformation state of carpet B-J-1 having the highest apparent density of pile yarn phase among tested carpets. When a compressive strain is applied, by a plain plate, on the carpet, compressed area of carpet is nearly equal to that of the plate. Since the compressive behavior of carpets is similar to those of materials with 0 in Poisson's ratio, the values of $\emptyset_{P}$ and $\emptyset_{B}$ related to thickness of carpet is given by eq. (2).

$$
\begin{aligned}
& l_{c}=l_{P}+l_{B} \\
& \Phi_{P}=l_{P} / l_{c}, \Phi_{B}=l_{B} / l_{c} .
\end{aligned}
$$

where $l_{P}$ and $l_{B}$ are thickness of pile yarn phase and that of base fabric phase, respectively.

3. Apparatus for Viscoelastic Measurement in Compression and Calculation Method of Viscoelastic Constants of Carpet

Many apparatuses to measure the dynamic behavior of high polymers and fiber materials have been designed ${ }^{[5]}$, but there are only a few for dynamic measurement in compression except those used for rubber materials.

Apparatuses to measure dynamic viscoelastic properties in compression of carpet need a sensitive and stable measuring device for dynamic force and dynamic amplitude, and require the frequency range of around $0.5 \mathrm{~Hz}$. in variation. The construction of apparatus used is schematically illustrated in Fig. 3.

Fig.4 is a schematic diagram showing the compressive stress-strain curve of carpet. The dynamic viscoelastic

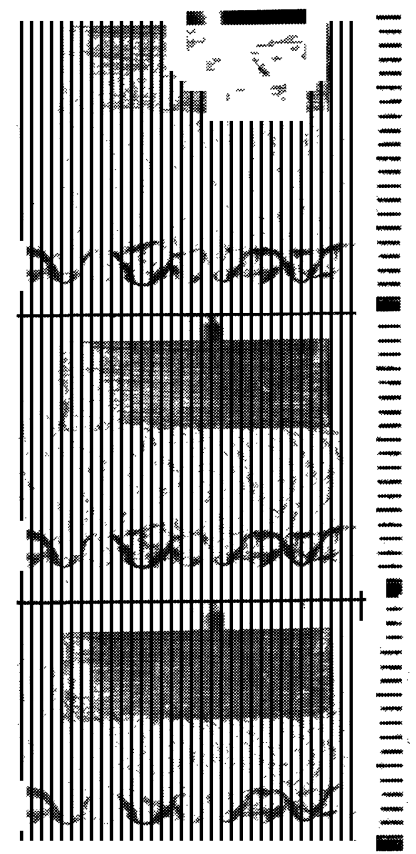

Fig. 2 Compressive deformed state of carpet B-J-1 having the highest value on $\mathrm{d}_{a}, p$ among sample carpets: uper; $\varepsilon=0 \%$, middle; $\varepsilon=20 \%$, lower; $\varepsilon=40 \%$, one scale at right side represents $1 \mathrm{~mm}$

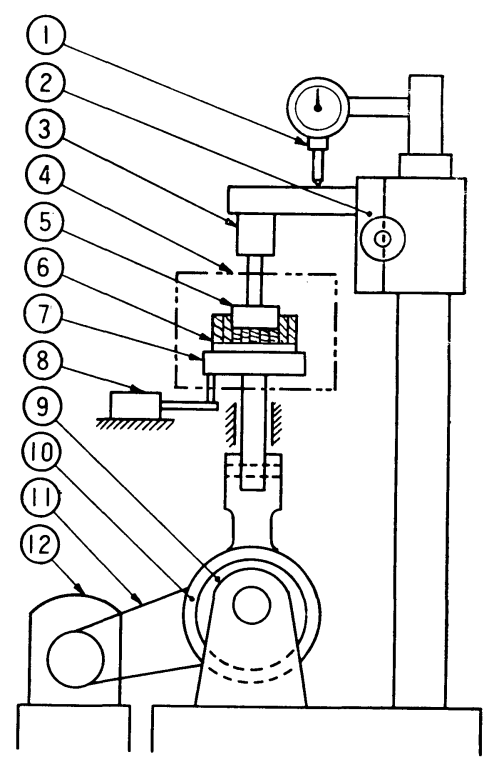

Fig.3 Schematic diagram of apparatus employed for viscoelastic measurement of carpet, 1: dial gauge; 2: rack and pinion adjustment; 3 : resistance strain gauge for force; 4 : oven; 5 : upper plate; 6 : sample carpet; $7:$ lower plate; $8:$ resistance strain gauge for strain ; 9: eccentric disc; 10: yoke; 11: V-belt; 12: variable speed motor 


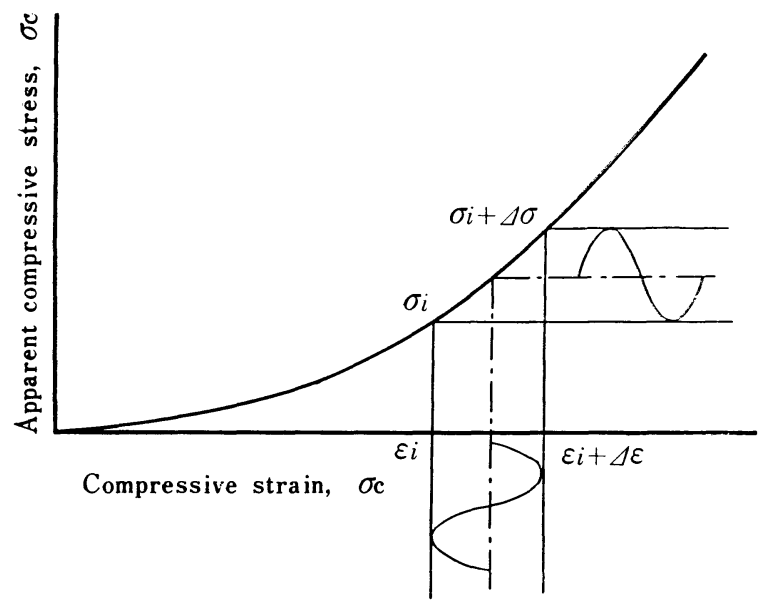

Fig.4 Schematic diagram of apparent compressive stress-strain curve for cut pile carpet and that of applied strain wave for dynamic measurement and of responsed force wave in carpet at any static strain

measurement was carried out under a small strain amplitude considered within the limits of linear relationship of stress-strain curve shown in Fig. 4.

In the experiments, a sample carpet is put on lower plate(7) and then, deformed to any static strain by the upper plate (5) connected to rack-pinion adjustment(2). Then, the eccentric disc (9) is driven by a variable speed motor (12) through the belt (11) in order to apply sinusoidal vibration to the sample carpet. Imposed force and applied amplitude during the vibration are picked up by resistance strain gauges to feed picked-up voltage to an $\mathrm{X}-\mathrm{Y}$ recorder through the amplifiers.

The dependence of frequency, temperature and static strain upon viscoelastic constants of carpet are measured by this apparatus under various conditions by changing driving motor speed, temperature in oven and magnitude of static strain.

Fig.5 is one of the typical records obtained by this apparatus for B-J-I carpet. Fig.5-a and Fig.5-b show a strain wave applied by means of the eccentric disc and picked-up force wave in carpet at any time, respectively. Picked-up voltage from the force wave is fed to $\mathrm{X}$-axis of the $X-Y$ recorder and the one from strain wave to its Y-axis. The trace is translated into a steady hysteresis loop shown in Fig. 5-d. Fig. 5-c shows how to obtain a steady hysteresis loop during the dynamic measurement of carpet by operation of this apparatus.

A shape of a steady hysteresis loop shown in Fig. 5-d is not elliptical. For this reason, in this experiment, apparent complex dynamic modulus for carpets are calculated from the measurable quantities, such as an area enclosed by the loop and an average slope of the center line of the loop.

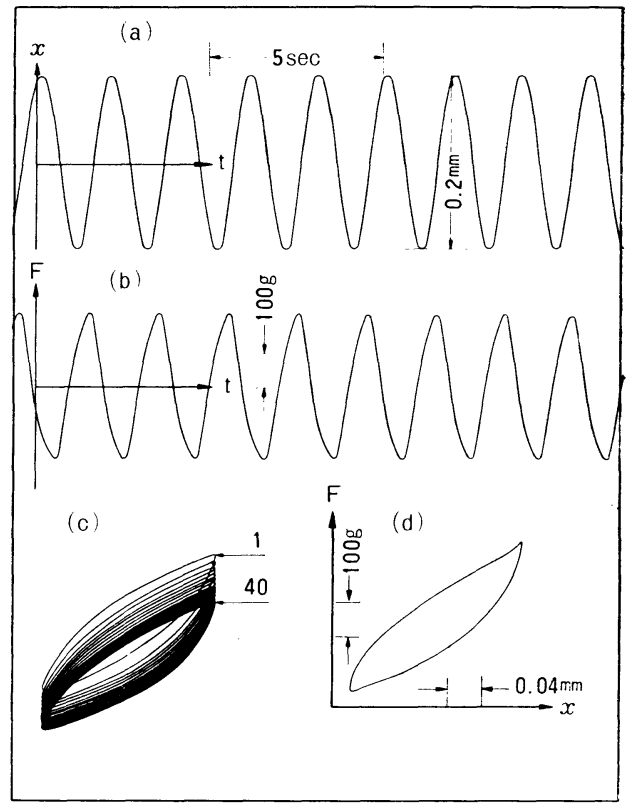

Fig.5 Typical records obtained by this apparatus for carpet B-J-1, (a): a strain wave applied on the carpet; (b): a force wave responsed in the carpet; (c): a process till the steady loop is obtaind; (d) : the steady hysteresis loop traced on $\mathrm{X}-\mathrm{Y}$ recorder

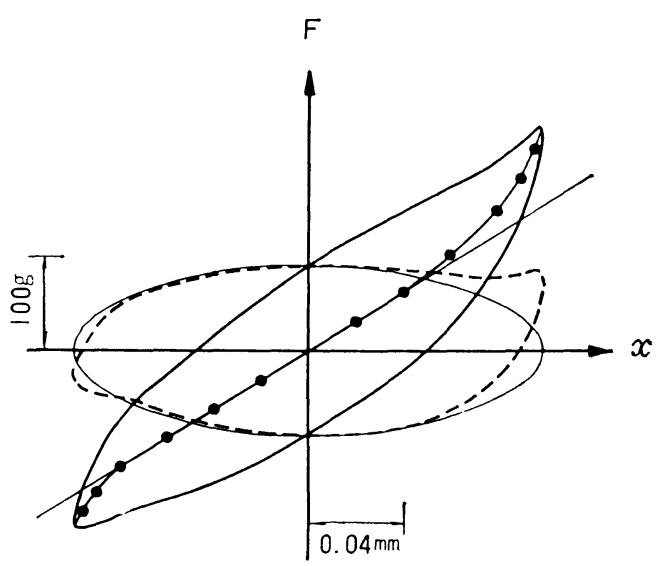

Fig.6 Traced histeresis loop and its backbone line for $\mathbf{B}-\mathbf{J}-1$ carpet. Thinner solid line shows a case where a linear viscoelastic body is used

Apparent storage modulus $E c^{\prime}(\omega)$ and loss modulus $E c^{\prime \prime}(\omega)$ at any observed frequency are given by eq. $(3)^{[6]}$, also,

$$
\begin{aligned}
& E_{c}^{\prime}(\omega) \doteqdot \alpha \cdot l_{c} / S \\
& E_{c}^{\prime \prime}(\omega) \doteqdot \frac{\mathrm{A}}{S \cdot l_{c}} \cdot \frac{1}{\pi\left(\frac{c}{l_{c}}\right)^{2}}
\end{aligned}
$$$$
\}
$$ 
where $s$ is a cross sectional area of upper plate in Fig.3, $A$ is an area of loop, $\alpha$ is an average slope of center line of loop, $l c$ is a thickness of carpet under applied static strain, $e$ is a magnitude of eccentricity of the eccentric disc.

Fig.7 shows hysteresis loops traced under constant sensitivity of amplifiers for carpet P-J applied various magnitude of static strains at constant frequency of $1 \mathrm{~Hz}$. With increasing applied static strain, values of the slope $\alpha$ and area $\boldsymbol{A}$ of hysteresis loops are changed.

\section{Experimental Results}

Figs.8 and 9 show the apparent complex dynamic modulus, $E_{c}{ }^{\prime}\left(\omega, \varepsilon_{0}\right) E_{c}{ }^{\prime \prime}\left(\omega, \varepsilon_{0}\right)$, over a frequency range from 0.05 to $1 \mathrm{~Hz}$. for the woven carpets with wool pile yarn and tufted carpet with synthetic pile yarn, respectively, which were measured at $65 \%$ R.H., $25^{\circ} \mathrm{C}$ under various static strains. As seen in the figures, $E_{c}{ }^{\prime}\left(\omega, \varepsilon_{0}\right)$ and $E_{c}{ }^{\prime \prime}\left(\omega, \varepsilon_{0}\right)$ are approximately independent of frequency within the observed frequency range. The other hand, these values are dependent on applied static strain.

Fig.10 shows the static strain dependence of the apparent complex dynamic modulus at $1 \mathrm{~Hz}$. for six kinds of carpets from the above results. $E_{c}{ }^{\prime}\left(\omega_{0}, \varepsilon\right)$ and $E_{c}{ }^{\prime \prime}\left(\omega_{0}, \varepsilon\right)$ are affected by the degree of apparent densities of two phases of carpet. Carpet B-J-1 having higher densities of $d_{a, P}$ and $d_{a, B}$ represents great values of $E_{c}{ }^{\prime}\left(\omega_{0}, \varepsilon\right)$ and $E_{c}{ }^{\prime \prime}\left(\omega_{0}, \varepsilon\right)$, $E_{c}{ }^{\prime}(\omega 0, \varepsilon)$ of carpet B-J-4 having lower density of $d_{a, B}$ increases rapidly with applied static strain and $E_{c}{ }^{\prime}\left(\omega_{0}, \varepsilon\right)$ and $E_{c}{ }^{\prime \prime}(\omega 0, \varepsilon)$ of carpet W-J-3 having lower $d_{a, P}$ and higher $d_{a, B}$ represent small magnitude and independence of applied static strain.
As seen in Fig.10, static strain dependence of complex dynamic modulus for tufted carpets is not affected by the kind of pile yarn materials.

\section{Discussion}

5-1 On the Structure of Two Phases for Carpet

By comparing a pile yarn phase with a base fabric phase, there is a difference in assembly of yarns and apparent density between the two phases. Consequently
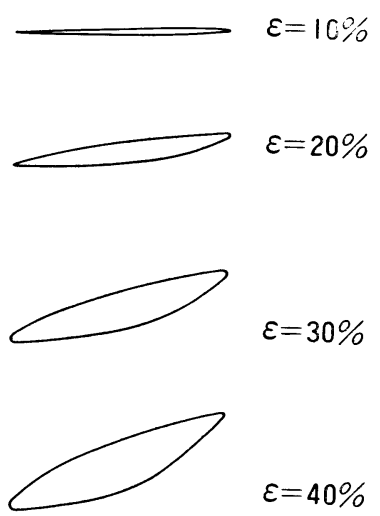

$$
\varepsilon=40 \%
$$

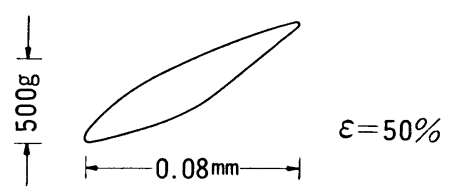

Fig.7 Hysteresis loops of carpet P-J recorded in static strain range 10 to $50 \%$

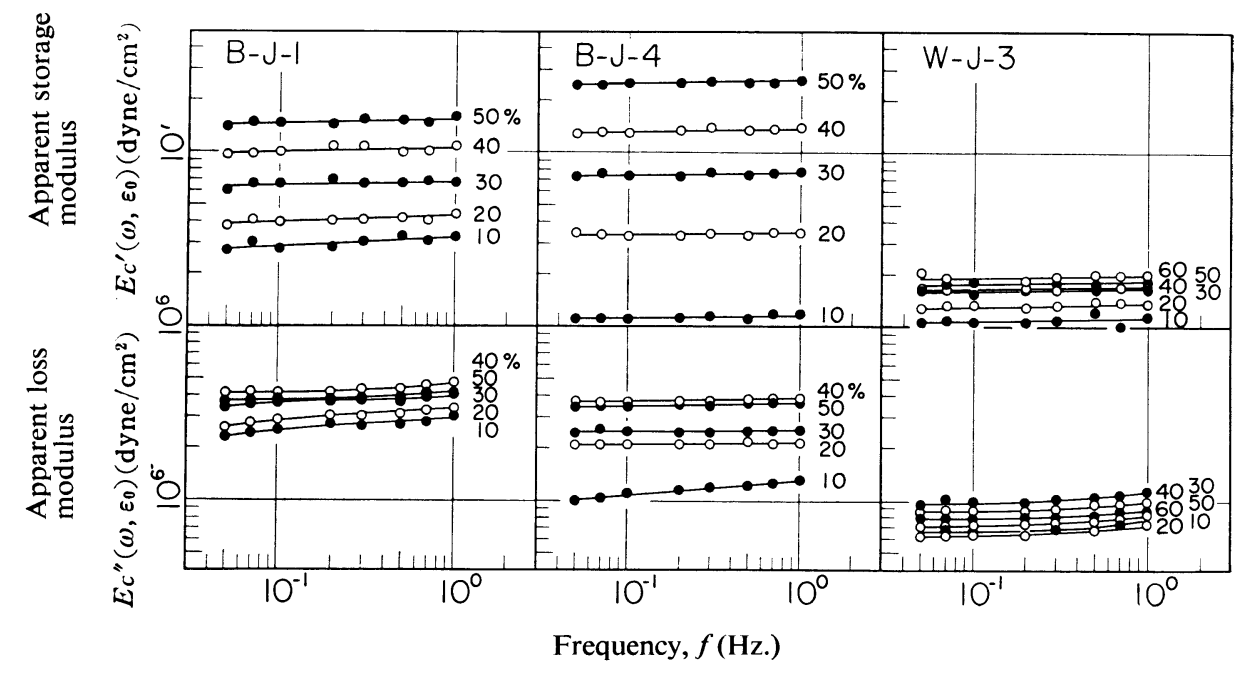

Fig. 8 Frequency dependence of apparent complex dynamic modulus of three woven carpets having variable apparent densities under static strain range 10 to $60 \%$ 


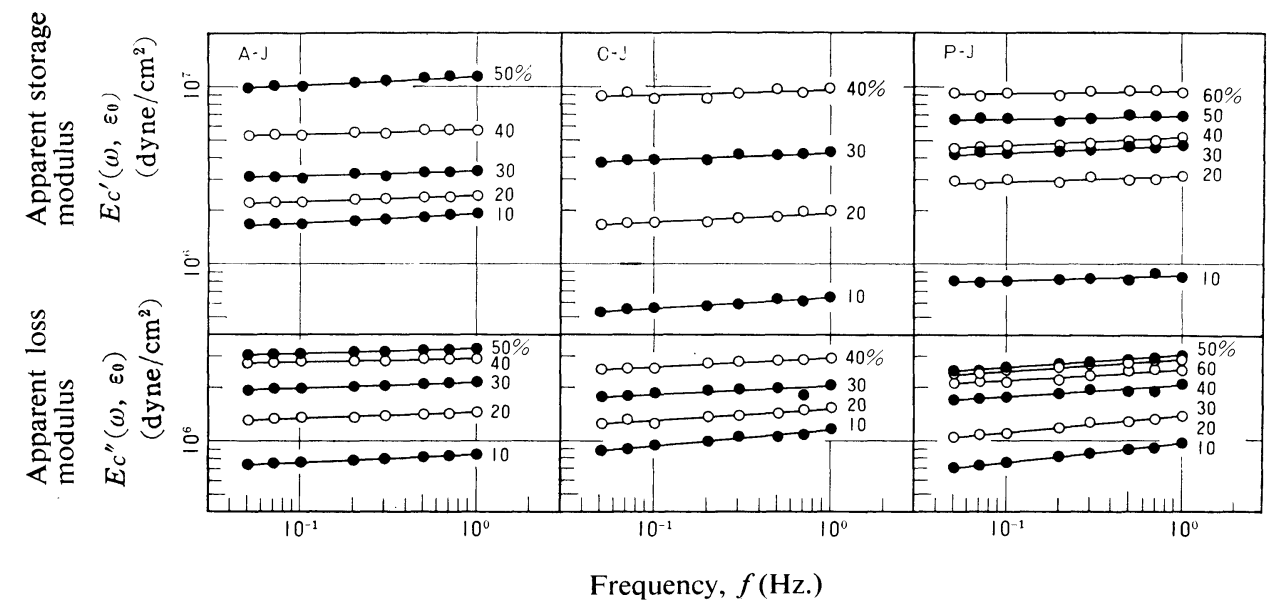

Fig. 9 Frequency dependence of apparent complex dynamic modulus of three tufted carpets with variable pile yarns under static strain range 10 to $60 \%$

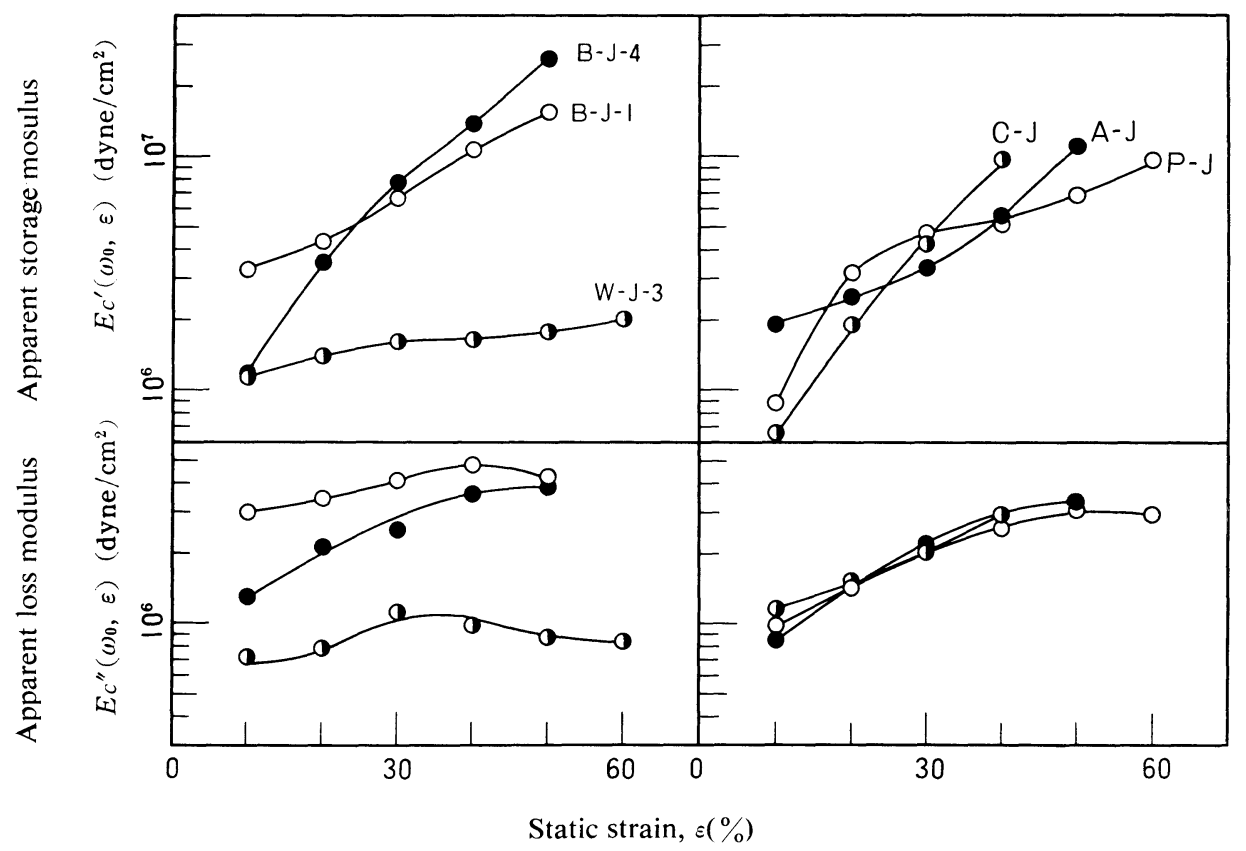

Fig.10 Static strain dependence of apparent complex dynamic modulus at $1 \mathrm{~Hz}$.

it is obvious that apparent values of $E_{P} *$ differ from one of $E_{B} *$. To explain degree of the difference between $E_{P} *$ and $E_{B}{ }^{*}$, complex dynamic modulus of base fabric, after pile yarns carefully are cut off from the carpet, is measured by this apparatus. Thus, the complex dynamic modulus of pileyarn phase, $E_{P} *$ can becalculated from the measured quantities $E_{C} *$ and $E_{B} *$ by using eq.(1).
In actual calculation, $E_{P} *$ may be defined by eq.(4) on following assumption that $E_{B}{ }^{*}$ is independent of static strain and pile yarn phase is imposed on with compressive deformation.

Apparent complex dynamic modulus of carpet A-J and that of each phase of the carpets calculated by eq.(4) are shown in Table 2. $E_{B}{ }^{*}$ has a higher modulus than $E_{P}$, * and 
Table 1 Material of Pile Yarn and Thickness and Apparent Density of Cut Pile Carpet Used

\begin{tabular}{|l|c|c|c|c|c|}
\hline Specifications & Material of & $\begin{array}{c}\text { Thickness of } \\
\text { carpet }\end{array}$ & $\begin{array}{c}\text { Thickness of } \\
\text { base fabric } \\
l_{B}(\mathrm{~mm})\end{array}$ & $\begin{array}{c}\text { Apparent density } \\
\text { of pile yarn phase } \\
d_{a, P}\left(\mathrm{~g} / \mathrm{cm}^{3}\right)\end{array}$ & $\begin{array}{l}\text { Apparent density } \\
\text { of base fabric } \\
\text { phase } \\
d_{a, B}\left(\mathrm{~g} / \mathrm{cm}^{3}\right)\end{array}$ \\
\hline W-J-1 & wool & 11.9 & 3.0 & $0.14_{5}$ & 0.45 \\
W-J-3 & wool & 6.5 & 2.1 & $0.10_{6}$ & 0.55 \\
B-J-1 & wool & 12.2 & 3.0 & $0.17_{5}$ & 0.52 \\
B-J-2 & wool & 8.7 & 2.9 & $0.13_{5}$ & 0.51 \\
B-C-3 & wool & 15.9 & 3.7 & $0.13_{8}$ & 0.57 \\
B-J-4 & wool & 8.7 & 3.6 & $0.11_{1}$ & 0.37 \\
P-J & polypropylene & 9.0 & 2.5 & $0.10_{9}$ & 0.46 \\
A-J & exlan & 11.9 & 3.2 & $0.10_{0}$ & 0.54 \\
C-J & cordelan & 8.2 & 3.8 & $0.14_{3}$ & 0.53 \\
\hline
\end{tabular}

Table 2 Apparent Complex Dynamic Modulus of Carpet A-J, and Volume Fractions and Complex Dynamic Modulus of each Phase of the Carpet under Particular Static Strains at $1 \mathrm{~Hz}$.

\begin{tabular}{|c|c|c|c|c|c|c|c|c|}
\hline $\begin{array}{l}\text { Static } \\
\text { strain } \\
(\%)\end{array}$ & $\begin{array}{l}\text { Volume fract. } \\
\text { of pile phase } \\
\qquad \phi_{P}\end{array}$ & $\begin{array}{l}\text { Volume fract. } \\
\text { of base phase } \\
\qquad \phi_{B}\end{array}$ & $\begin{array}{l}E^{\prime}\left(\omega_{0}, \varepsilon\right) \text { of } \\
\text { carpet } \\
\left(\text { dyne } / \mathrm{cm}^{2}\right)\end{array}$ & $\begin{array}{l}E^{\prime \prime}\left(\omega_{0}, \varepsilon\right) \text { of } \\
\text { carpet } \\
\left(\text { dyne } / \mathrm{cm}^{2}\right)\end{array}$ & $\begin{array}{l}E^{\prime}\left(\omega_{0}, \varepsilon_{0}\right) \text { of } \\
\text { base phase } \\
\left(\text { dyne } / \mathrm{cm}^{2}\right)\end{array}$ & $\begin{array}{l}E^{\prime \prime}\left(\omega_{0}, \varepsilon_{0}\right) \text { of } \\
\text { base phase } \\
\left(\text { dyne } / \mathrm{cm}^{2}\right)\end{array}$ & $\begin{array}{l}E^{\prime}\left(\omega_{0}, \varepsilon\right) \text { of } \\
\text { pile phase } \\
\left(\text { dyne } / \mathrm{cm}^{2}\right)\end{array}$ & $\begin{array}{l}E^{\prime \prime}\left(\omega_{0}, \varepsilon\right) \text { of } \\
\text { pile phase } \\
\left(\text { dyne } / \mathrm{cm}^{2}\right)\end{array}$ \\
\hline 10 & 0.70 & 0.30 & $1.88 \times 10^{6}$ & $1.70 \times 10^{6}$ & $5.11 \times 10^{7}$ & $9.42 \times 10^{6}$ & $1.32 \times 10^{6}$ & $1.21 \times 10^{6}$ \\
\hline 30 & 0.61 & 0.39 & 3.25 & 2.10 & 5.11 & 9.42 & 1.98 & 1.34 \\
\hline 50 & 0.46 & 0.54 & 11.0 & 3.30 & 5.11 & 9.42 & 1.10 & 3.48 \\
\hline
\end{tabular}

$E_{P} *$ has the same order of $E_{C} *$. As the results, viscoelastic behavior of carpets under static strain of less than $50 \%$ is influenced by that of the pile yarn phase.

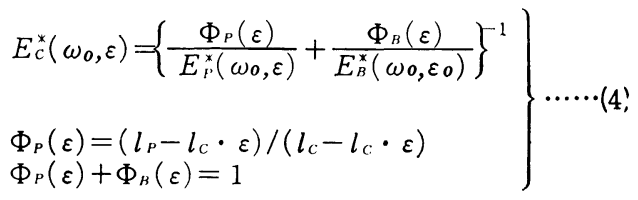

5-2 Relation between Complex Dynamic Modulus and Apparent Density of Pile Yarn Phase

As shown in Fig.9, the values of complex dynamic modulus for cut pile carpet produced of the same fiber material are influenced by the magnitude of apparent densities of each phase of the carpet. Therefore, the regions of $E_{c}{ }^{*}$ measured under static strain range from 10 to $50 \%$ at $1 \mathrm{~Hz}$. for all sample carpets have been plotted against the apparent density of pile yarn phase in Fig. 10.

From the standpoint of floor absorber, it seems that the carpet higher in value of $E_{C}{ }^{*}$ and less affected by above mentioned static strain range, may be better in quality.

Some carpets having the value of $\sim 0.10 \mathrm{gr} / \mathrm{cm}^{3} \sim$ have a closer behavior to B-J-1 than some carpets of $\sim 0.14$ $\mathrm{gr} / \mathrm{cm}^{3} \sim$. The results show the complex dynamic modulus of carpets are influenced by some factors, such as kind of fiber material, crimpness of fiber, shape of cross section of fiber and yarn, twist structure of pile yarn and structure of base fabric.

\section{Conclusion}

An apparatus has been devised for the experiment to evaluate compressive viscoelastic behavior of carpets. Using the apparatus, apparent values of complex dynamic modulus have been measured by means of Hysteresis loop method for some cut pile carpets with the frequency range from 0.05 to $1 \mathrm{~Hz}$. under static strain of less than $60 \%$.

In the experiment, the structure of cut pile carpet is assumed a simple blend system, which consists of a pile yarn phase and a base fabric phase coupled in series. The 
carpet behaves just like a porosity material which has no closed air phase when compressed tightly.

To describe the compressive behavior of cut pile carpet, this study takes the mechanical model of the carpet as a

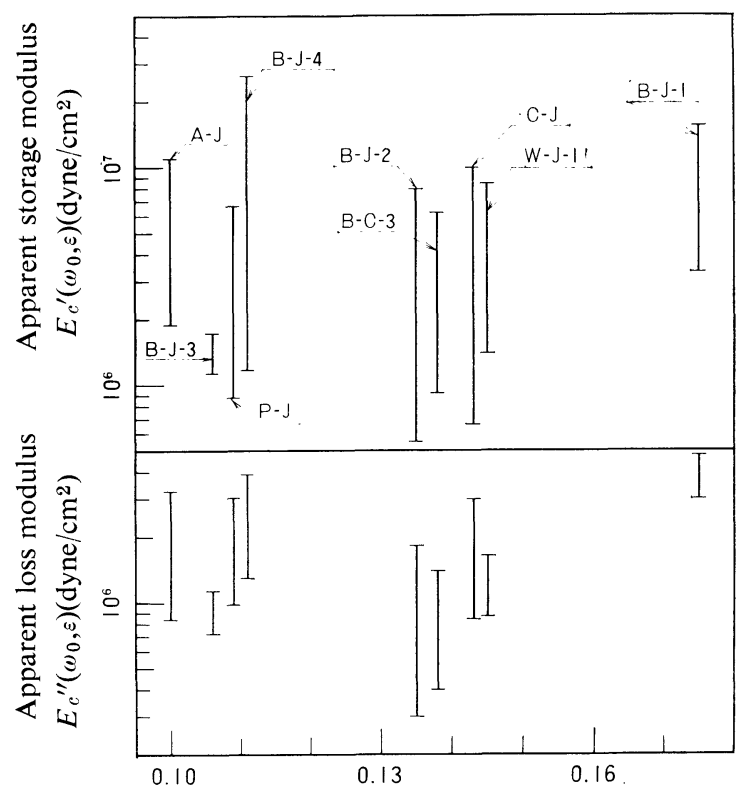

Apparent density of pile yarn phase, $d_{a, P}\left(\mathrm{~g} / \mathrm{cm}^{3}\right)$

Fig. 11 Regions of apparent complex dynamic modulus of sample carpets measured under static strain range 10 to $50 \%$ at $1 \mathrm{~Hz}$.
Voigt model representing linear viscoelasticity. In the practical aspect of behavior, carpet is represented by non-linear viscoelasticity shown in Fig. 5-d. Then, it is necessary to develop an experimental method to evaluate non-linear viscoelastic behavior of carpet.

The complex dynamic modulus for some commercial carpets resemble, in the apparent values, these of rubberlike materials. Accordingly, carpet is a floor material to act as part of absorber.

Also, the values of $E_{C}$ * for cut pile carpets produced with fibers having higher modulus are lower than these of fiber materials. The matter on this mechanism is a problem to wait for a later investigation.

\section{Literature cited}

[1] T. Horino and S. Kawanishi; J. Japan Res. Ass. Text. End-Uses, 9, 204 (1968)

[2] T. Horino and S. Kawanishi; ibid, 10, 213 (1969)

[3] F. C. Aarper, W. C. Warlow and R. L. Clarke; National Building Rearch Paper, p 32 (1961)

[4] M. Takayanagi, H. Harima and Y. Iwata; Zairyo, 12, 389 (1963)

[5] See, for example, R. Meredith and J. W. S. Hearle; "Physical Method of Investigating Textiles" Chap. 8, Interscience Publishers, Inc., New York (1959).

K. Fujino, H. Kawai, T. Horino and K. Miyamoto; J. Text. Mach. Soc. Japan, 1, No. 2, p.1 (1955)

[6] K. Fujino, K. Miyamoto, T. Horino and H. Kawai; Kobunshi Kagaku, 15, 713 (1958) 